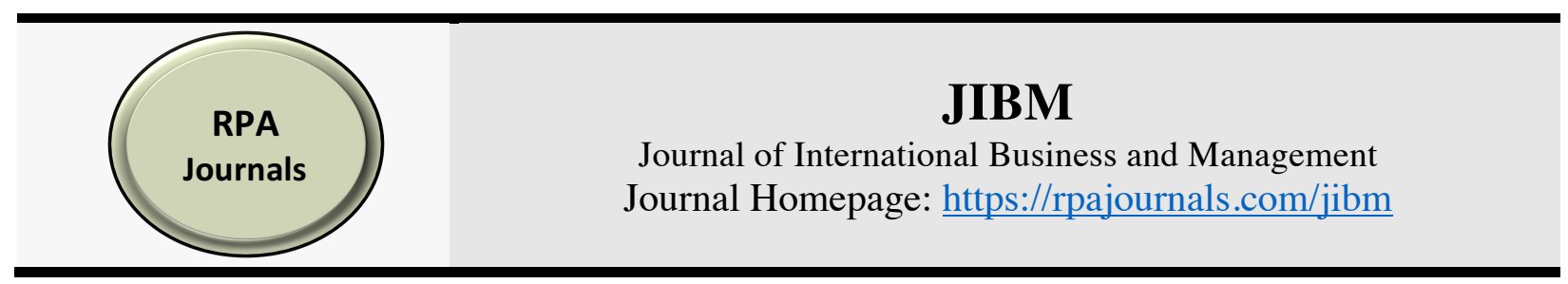

\title{
Talent Management Practices in Institutions: Impact of Recruitment and Culture on Employee Performance
}

\author{
Abdulkarim S. Praise*1 \\ Jainaba M. L. Kah ${ }^{2}$ \\ American University of Nigeria, Nigeria ${ }^{1,2}$
}

\begin{abstract}
The performance of institutions of higher learning in Nigeria is becoming a concern and an attention-grabbing issue to stakeholders and organizations, as a result of the severe shortage of employees, students and talent drain and attrition, poor quality graduates, poor global ranking, poor-quality research, and many others. This study examines Talent Management Practices in IHL: the impact of recruitment and culture on employee performance. The research design was based on the quantitative technique. Data was collected through a structured questionnaire using the Linkert scale. Data was analyzed using Partial Least Square Structural Equation Modeling (PLS-SEM). The researchers used the PLS model because the study involved testing a theoretical framework from a predictive perspective and our objective is to better understand an increasingly complex variable by exploring theoretical extensions on TMP. The findings of the study showed a positive relationship between TMP and Employee Performance. The implication is that for IHL to achieve efficiency, they must continue to invest in TM by selecting employees based on qualification, experience, and competence across all cadres; implement salary increment meritoriously; maintain transparency and not politicize promotion guidelines, and through public recognition and awards ingrain EP as part of the operational culture.
\end{abstract}

Keywords: Talent Management Practices, Employee Performance, Organizational Culture, Institution of Higher Learning.

*Corresponding author: Abdulkarim S. Praise; Email: praise.abdulkarim@aun.edu.ng

DOI: https://doi.org/10.37227/jibm-2020-02-14

\section{Introduction}

Talent management has witnessed several studies in the last decades and most of these studies were conducted in profit-making business organizations with a little or neglected emphasis on institutions of higher learning (Lunch, 2006; Thunnisen et al., 2013). Most of the studies used Statistical Product for Social Sciences (IBM SPSS) in data analysis, which is a limited model compared to PLS-SEM used in this article.

Institutions of higher learning (IHL) are service rendering organizations that proffer opportunities for undergraduate and graduate education. In Nigeria, IHL are facing several challenges such as severe shortage of employees, talent and student drain and attrition, poor-quality graduates, 
poor-quality research, inadequate budgetary allocation, poor global ranking, and many others. This situation has led to the increasing culture of visiting lectureship where the few available talents are recycled as visiting, adjunct, sabbatical, and contract lecturers to work in many institutions at the same time.

The performance of IHL is becoming a concern and an attention-grabbing issue to both national and international bodies. As a result of the global emergence and prominence of the knowledge-driven economy, IHL today compete in the global market for both students and employees (Saint, 2015). There is also a notable concern of brain drain, talent attrition, poor-quality graduates, and huge capital flight abroad on students' enrolment. IHL are losing over 75,000 students yearly with tuition fee worth over \$2bn (over 720 billion naira equivalent) on abroad studies (Senate Committee Report on Tertiary Institutions, 2016). Employers of labour believe that university graduates are poorly trained and unproductive on the job (Dabelen, et al., 2002; Praise \& Lukman 2020). Salmi (2009) believed that the concentration of talent is a determining factor in accessing the high performance of IHL. Therefore, TMP can contribute to educational excellence in IHL (Lynch, 2007; Riccio, 2010; Ogbari et al., 2018). Despite the importance of TMP in IHL, only a few institutions have implemented formal programs to support and promote existing talent; IHL continue to pride themselves on learning and advance thinking but place no emphasis on TMP and therefore invest little or no time on TM (Riccio, 2010; Ogbari et al., 2018).

Groysberg and Bell (2013) believed that one of the reasons IHL fail to identify TMP accurately on time is because they are not able to incorporate TM programs into the strategic plan of the institutions. Since IHL are reservoirs of knowledge, they have a critical role of fostering the needs of human resources and satisfying the aspirations of people to build a prosperous and humane society. To stay globally competitive, IHL need to benchmark to allow efficient implementation, review, and enhancement of TMP to improve employee performance (Liversage, 2015).

IHL need to seriously engage in a paradigm shift regarding their TMP if they are to succeed and sustain a competitive advantage. The trend in studies showed that employee performance and reward programs are not connected and unable to support effective and robust TMP in IHL; attention to employees' development and succession planning is still very low; and commitment to employee monitoring and engagement as an operational cultural practice is still very low in IHL (Norman, 2014). Therefore, it is imperative to examine the impact of TMP in IHL in Nigeria.

Studies revealed that people and not institutions generate value, that talents are the most vital resources in any organization and they provide the knowledge, skill, research, teaching, and development that inform graduates and are used as a basis for ranking IHL (Bush et al., 2020, Bradley, 2016; Mckinsey \& Company, 2020). Quality education is depended on the commitment and quality of talents and the institution's operational culture (Bush et al., 2020). The business organizations focus on quality products to win the heart of their customers, IHL in the same strategy must focus on developing their talents who in turn train the graduates (Davies \& Davis 2019). The problem is that IHL invest time and resources in developing their students with corresponding inadequate developmental programs and investment in their employees (Lynch, 2007). Emphases on talent recruitment and selection as well as operational culture are as important as care for students if IHL must ensure quality service delivery. Some of the key concepts underpinning quality education today include talent recruitment and selection, talent motivation and reward, talent retention, training, coaching, and mentoring of talent, and many more (Bush et al., 2020; Ansar \& Baloch, 2018). Therefore, TMP is a vital strategy for achieving success in IHL because it provides the muchneeded path for academic and employee development.

The IHL needs to accelerate development for academics (Mohan, Siva \& John, 2016). TMP (TRMP and TCMP) can be used to provide these much-needed paths. Given the critical role played by IHL in the nation's economy, there is a need for TMP to enhance institutional competitive advantage to survive in the global marketplace. The study developed hypotheses to test if any significant relationship exists between TMP and EP as thus:

i. There is no significant relationship between TMP (recruitment) and EP in IHL.

ii. Talent management practice (culture) has no significant relationship on EP. 
The remaining parts of this article is structured into four- literature review; methodology; analysis of data; and findings and recommendations.

\section{Literature Review}

IHL today battle for students and talented professionals across the globe, this is a reflection of Mckinsey's assertion in a study titled war for talent that submits that business organization should initiate TMP as a solution for today's labour market competitive problems (Mckinsey, 1998; Hosen, Islam, Arshad, Khan \& Alam, 2018). Though TM has no accepted definition, it is an effective management strategy for promoting employee wellbeing and the architecture required to develop and sustain employees' competitive advantage (Collins \& Mellahi, 2009). TM is critical and needed for the success of IHL (Armstrong \& Baron, 2007; Davies, \& Davies 2010). A strategic talent management practice and policy is required to effectively recruit and retain the right talent, and develop highly valued workforce (Tripathi, Jayanthi \& Pandeya, 2010; Hosen et al., 2018)

IHL need to adopt the TM strategy in managing employees and positions at all levels within the institutions. Haizam and Saudi, (2014) submits that TM is a strategy for attraction, training, development, and mentoring of the employees in organizations for efficient performance. Insights from previous studies and literature showed three perspectives on TM. First, TM as HRM rebranding; second TM focus is on internal and external talent using HR instruments; and thirdly, TM as a focus on talent flows management progression in an organization.

IHL across the world are adopting TM strategy to enhance employee performance (Bradley, 2016). In Australia and the United Kingdom, IHL in autonomy and deregulated market environment are adopting TM strategy to tackle challenges to improve employee performance and sustain competitive advantage (Peller, 2007, Bradley, 2016). In European and the United States of America, IHL offer developmental programs for administrative and teaching professionals, devising strategies in attracting the best talent in academics, giving full support to scientist, inventors, and researchers in providing opportunities for scholarship, merit and excellence-based (Riccio, 2010; Mugdha \& Sanhita, 2015)

IHL in the twenty-first century is considering the best talents as one of their strategies to sustain competitive advantage (Johnson, 2014; Knott, 2016). Therefore, adequate investment in employees' development becomes a strong predictor of a country's strength in developing and retaining its talent pool. One of Nigeria's governments' recent education and training reform, Tertiary Education Training Fund (TETFund) emphasizes the need for talent development as a key enabler for a sustainable economy and human capital development. However, the TETFund strategy has been counterproductive and has not been able to address the need for employees' performance management practices in IHL due to corruption, lack of accountability, and politicization of operations or favoritism.

\section{Underpinning Theories}

There are several contributions by various scholars that have examined the relationship between TMP and EP. Some of these relevant theories serve as a dependable framework and the study is built upon them. Specifically, the study highlighted the resource-based view and human capital theories. The resource-based view (RBV) maintains that "firms possess resources, a subset of which enables them to achieve a competitive advantage and a subset of those that lead to superior long-term performance." Valuable resources are rare and can lead to the creation of competitive advantage. The advantage created can be sustained over some time to the point that the firm can protect against resource imitation, transfer, or substitution. The resource-based view maintained that organizations and talent managers must engage in valuable resource investment in talented employees' competitive advantage (Petkovic \& Dordevic, 2013; Acar \& Yener, (2016). Although the resource-based view postulated a superior argument on talent management, Tetik, (2016) maintained that the RBV is inadequate in determining the motive behind talent management practice. 
The Human Capital Theory (HCT) is a modern extension of Adam Smith's explanation of wage differentials by the net disadvantages between different employments. The HCT emphasized TM as an investment in employees that gain high returns for owners and shareholders (Axelrod, 2001; Acar \& Yener, (2016). It posits that organizations must invest in their talented employees through recruitment, training, and development to achieve a competitive advantage. The HCT maintained that organizations could improve productivity and performance if they invest in employees through training, recruitment, education, and rewards management system (Acar \& Yener, 2016). A further belief is that widespread investment in human capital creates in the laborforce the skill-base indispensable for economic growth.

The HCT emphasized that investment in education is key, and for employees, human capital investment comprises both direct costs and costs in foregone incomes. Employees taking the decision to invest should compare the attractiveness of alternative future income and consumption streams, to know which offers enhanced future income, as an exchange for higher present training costs and deferred consumption. Human capital investment (social investment) returns can be calculated analogously. Empirical studies have suggested that, though some of the observed variations in earnings are likely to be due to skills learned, the proportion of unexplained variance is still high, and must be an attribute of the imperfect structure and functioning of the labor market, rather than of the productivity of the individuals constituting the labor supply.

\section{Talent Management Practice (Recruitment)}

The management of talent would be a complete effort and resources in futility without having a good attraction process. TM is the process or activity involved in attracting and enticing people who are qualified, competent, skillful, experienced, and capable in an organization (Davies \& Davies, 2010). For any organization to be successful and to maintain a competitive advantage, they must stay ahead by predicting those who will be the main drivers of the organization's future (Hay Group, 2008, cited in Davies \& Davies, 2010; and Mohan, Siva, \& John, 2016). IHL must be future-focused, predict what skills will be needed for the future of the institution, and recruit in line with competency, skills, and experience of the future needs. Recruitment in IHL requires the use of selection tools, which include an application form, evaluation of resume, tests, interviews, physical examination, reference, and background checks. Applying adequate methods of recruitment might reduce business costs and verse versa. Mwanzi, Wamitu, and Kiama (2017) emphasized the importance of recruitment methods in reducing the cost of business. A study conducted in Kenya to determine the influence of talent management on organizational growth and performance using talent identification shows a positive relationship between talent identification and organization growth and performance. Asiyai (2013), in a study "challenges of quality in higher education in Nigeria in the 21st century," revealed that poor quality of teaching staff and inadequate staff development programs, among others, result in poor quality service delivery and economic development.

Agrawal (2010), in a study "talent management model for business schools: factor analysis," conducted in India, showed a positive relationship between talent management recruitment and business school performance. The study further established business schools should understand and maintain faculty as talents and create an enabling work environment to harness their potentials. Ogbari et al. (2018), in a recent study "talent management as a determinant of firm performance: A conceptual approach," advocates continuous training, development, and recruitment of talent to obtain the required level of capacity of employees and improve organizational performance. Nafei (2016), in a study "the impact of talent management on organizational performance (OP): evidence from the industrial companies in Egypt," showed a positive relationship between TM recruitment and OP. Arif and Uddin (2016), in a study "talent management and organizational performance: an empirical study in the retail sector in Sylhet city, Bangladesh in South Asia, revealed a positive relationship between talent attraction and selection and OP. 


\section{Talent Management Practice (Culture)}

Culture is the tenets and mores of an organization (Coetsee 2004; Nafei (2016). Organizational culture is a set of beliefs and values that an employee subscribes to in an organization (Magee, 2002; Maina, 2016). These beliefs are products of reality and experience, while standards are desirable ideals worth sharing. They are a specific assortment of principles shared by all employees in an organization. Beliefs and values control the behaviors of individual employees and groups within the organization; this way, employees interact, relate, and intermingle with the internal and external environmental variables. Talented professionals need to have the impression that they are valued and their contribution worth a competitive advantage to the organization (Davies \& Davies, 2010). The need for good corporate culture as a retention strategy has become an area of focus for researchers (Philip \& Cornel, 2003; Nafei, 2016). Managers and institutional authorities must align management and the organization's expectations with the overall corporate culture (Ahlrichs, 2003; Nafei 2016; Islam, Jantan, Rahman, Hamid, Mahmud, \& Hoque, 2018). Organizational culture has a direct impact on many variables of the organization (Kotter, 2012; Nafei, 2016). If the norm and values guide employees in an organization in terms of operations, it will impact and improve their performance (Hofstede, 2007; Nafei, 2016). Sharkey and Eccher (2011) and Mohan, Siva, and John (2016) believe that in organizations with good supportive culture employees can achieve a 30\% increase in business results. Any organization with a well-defined and stipulated culture and common goals is likely to attain more efficiency since workers share the same ideals and orientation for success.

James and Justus (2012), in their recent study on the impact of organizational culture on performance of educational institutions in Kenya, showed that every organization (whether business and education) has a culture, whether good or bad. They outlined three criteria needed by the organization to develop a suitable culture and to aid long term performance. Firstly, organizational culture should be strategically relevant to the mission and objectives of the organization. Second, organizational culture needs to be strong to attract attention; care and respect of the people, and third, organizational culture should have an "intrinsic ability" to adjust to the changing and prevailing circumstances. The study revealed that culture has a positive influence on an employee's attitudes to work and that there is a close relationship between organizational culture and organizational performance. Aibieye and Igiebor (2015), in the study "talent management and employee retention in Nigerian universities," show a positive and significant impact on organizational culture.

Managers and stakeholders of IHL must engage valuable investment in talents to sustain institutional performance (Acar \& Yener, 2016). In the UK and Australia, institutions through autonomy in a deregulated market environment are adopting TM strategy to tackle challenges (Peller, 2007; Bradley, 2016). TM is an appropriate strategy used by institutions to transform employees into strategic resources. The IHL in Australia and the United Kingdom used TM to boost academics teaching and research by identifying pivotal, high value-added, roles in teaching, and research (Bradley, 2016). Though there are no supporting studies on IHL research and graduates' performance, it is important to note that research drives universities' global ranking (Bradley, 2016). Research quality drives universities' competitive advantage from its competitors; it drives university global reputation which is an important factor that impacts student choice of an institution as operational culture (Bradley 2016). The IHL in Nigeria should embrace the TM strategy to create an enabling operational culture where employees' competencies and skills can improve their roles in teaching and research. This will boost the global ranking of the institutions and once this is achieved, it will impact the enrolment of students to generate more funds. From a TM perspective, IHL must emphasize recognition of skills and award competence as an operational culture to boost teaching and research.

The world strives today on knowledge economy and IHL are the reservoir of knowledge in every nation. To have a strong nation and strong economy, talents in IHL must be developed to produce the graduates that will be employed by public and private organizations. TM becomes inevitable in IHL if they must achieve this goal. IHL must consciously recruit and select the best employees across cadres meritoriously (Daudi, 2008). Organizations scramble for quality talents and once emphasis on TM is low and not given priority, many talents will prefer to work abroad and in highly rated institutions to be relevant to the national and international economies (Woo, 2014). 
Employee turnover and talent drain abroad are high in IHL in Nigeria because of job insecurity, insufficient rewards, poor management practice, harsh working environment, and workload (Lanre $\&$ Abosede, 2018). TMP can be adopted to address these challenges.

A study of the United Kingdom organizations revealed that TM is critical for developing successful organizations including educational institutions for future direction and leadership (Davies \& Davies 2017; Khan et al., 2019). Another survey in the United Kingdom showed that authorities of institutions must train and nurture talent to discover their unique skills and capitalize on the skills to enhance performance; since employees in IHL are typically associated more with their discipline than the university, TM becomes critical at organizational and institutional levels in balancing effective management and academic autonomy (Winter, 2009; Bradley, 2016; Tony, 2020). A scientific and qualitative study conducted in the United States of America revealed that TMP has a positive significant impact on employee success (Riccio, 2010). A study of the Australians' tertiary institutions showed that there is a positive relationship between TMP and employee performance (Mohan et al., 2018). A cross-sectional quantitative study of the Chinese firms revealed that TMP has a significant positive relationship on employee cost and performance (Raymond et al., 2016). Indonesian firms' study revealed that TMP has a direct positive influence on employee performance (Saud et al., 2016). In Malaysian, a study of TMP in public universities showed a positive and significant relationship on institutional success (Ishak \& Akmal, 2016). A study on the international business school in NOIDA, India, revealed that TM strategies (attracting, motivating, training and development) has a positive relationship on educational institutions' employee performance and can be used to provide solutions to the shortage of competent and qualified faculties in educational institutions (Erkan et al. 2017).

A study of Botswana's higher education in Africa revealed that TMP is still work in progress due to the inability of managers and stakeholders to plan and implement TM programs to enhance employees' performance (Norman \& Cosmas, 2017). In a study of higher education in South Africa's empirical survey revealed that TMP is essential to employee development, that institutions are aware of innovation sources that are currently used in managing talent in their division and faculties, and TM is associated with innovation speed of the institutions (Atheer et al., 2018). A quantitative study of the Egyptian banks showed that TM has a positive and significant relationship on employee performance in financial institutions (Nafei, 2015). A cross-correlation study in Kenya's business organization showed a positive relationship between TMP and employee performance (Knott, 2016). Also, a study of educational institutions in Zimbabwe revealed a positive relationship between TMP and institutional success (Mahlahla, 2018).

Studies undertaken in Nigeria on TM in the banking sector in Delta State revealed that TMP is essential for employee survivability and viability of business organizations (Kalu, Ezianshi, \& Okoro, (2017). Despite the importance of TM, IHL proud themselves on investing in their students almost to the neglect of their talents (Lunch, 2007). The institutions must put the need of their talents first by investing in them instead of the exploitation approaches currently in practice (David, 2017). Institutions must take responsibility for their TMP and this will increase enrolment of students, improve employee performance, improve quality graduates, and reduce students' drain abroad. Though similar talent needs and aspirations may exist between developed and developing nations (including sub-Saharan Africa and Nigeria), there is a paucity of literature to benchmark TMP in IHL in Adamawa State and a gap between what is obtainable in the developed world and developing world, particularly in Nigeria in terms of demand for quality service. This knowledge gap provides the basis for this study; which aimed at examining TMP in IHL: the impact of recruitment and culture on employee performance in Adamawa State, Nigeria. 


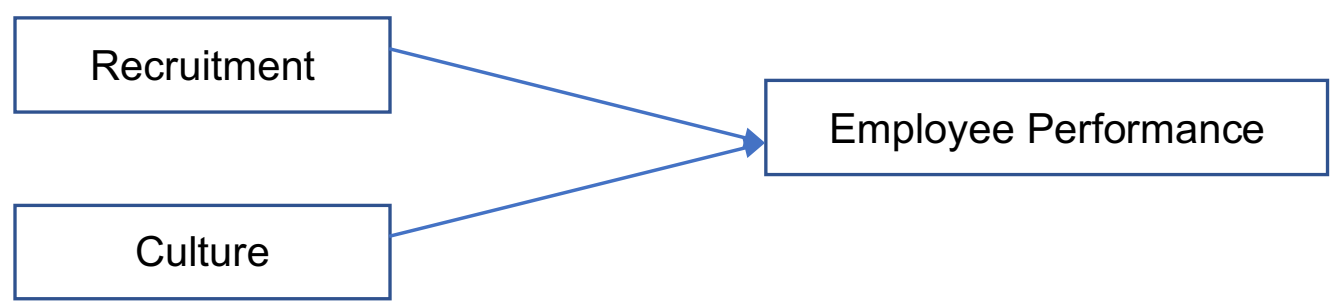

Figure 1: A Conceptual Model

\section{Research Design}

\section{Methodology}

The researchers adopted a quantitative survey design that was used to collect data and explore the topic under study. The survey was appropriate to enable the researchers to formulate significant principles of knowledge and to test a theory, to evaluate a program, or to accurately describe and assess meaning related to an observable phenomenon (William, 2006).

The study was conducted in Adamawa State (north-eastern, Nigeria) and the state capital is Yola. The State has 21 local government areas. The study included all the employees at the IHL in Adamawa, selected from four local government areas (Yola South, Girei, Hong, and Mubi North) based on location. The employees were considered from different hierarchical levels (that is Assistant lecturer to a professor and administrative to decision-making divisions) randomly selected across faculties and departments in the institutions. An updated population size of 8355 employees was obtained through the researchers' visit to the HR departments of the different and used in this study. The researchers informed the institutions that the information requested is strictly for academic study purposes and employees' names and units will be converted into pseudo names and identities. The sample size is 382 obtained through random selection using Taro Yamani's formula (1967).

Table 1: Sample Size Distribution

\begin{tabular}{|l|c|c|c|}
\hline \multicolumn{1}{|c|}{ Institution } & Employees & Percentage & Sample size \\
\hline $\begin{array}{l}\text { Modibbo Adama University } \\
\text { of Technology, Yola }\end{array}$ & 2203 & 26.4 & $2203 / 8355 \times 382=101$ \\
\hline $\begin{array}{l}\text { American University Of } \\
\text { Nigeria, Yola }\end{array}$ & 1253 & 15 & $1253 / 8355 \times 382=57$ \\
\hline $\begin{array}{l}\text { Adama State University } \\
\text { Mubi }\end{array}$ & 1288 & 15.4 & $1288 / 8355 \times 382=59$ \\
\hline Federal Polytechnic Mubi & 1332 & 15.9 & $1332 / 8355 \times 382=61$ \\
\hline $\begin{array}{l}\text { Adamawa State Polytechnic, } \\
\text { Yola }\end{array}$ & 1359 & 16.3 & $1359 / 8355 \times 382=62$ \\
\hline $\begin{array}{l}\text { Federal College of } \\
\text { Education, Yola }\end{array}$ & 489 & 6 & $489 / 8355 \times 382=22$ \\
\hline $\begin{array}{l}\text { State College of Education, } \\
\text { Hong }\end{array}$ & 431 & 5 & $431 / 8355 \times 382=20$ \\
\hline & $\mathbf{8 3 5 5}$ & $\mathbf{1 0 0}$ & $\mathbf{3 8 2}$ \\
\hline
\end{tabular}

The study used a questionnaire adopted from Knott (2016), Maina (2016), and Liversage (2015); modified the content, context, and the number of questions; vetted by experts and used as the primary instrument of data collection. The questionnaire was structured, undisguised, and logical with no follow-up questions. The same questions were administered to all respondents in the institutions.

The researchers engaged Assistants to distribute the questionnaire to three institutions and goggle forms technology was used to cover the remaining institutions. 382 questionnaires were distributed and 381 were filled and returned. This represents a $99.7 \%$ response rate. The response 
rate was high because of adequate follow-up and the use of technology to distribute questionnaires to institutions. The respondents were given twenty-four hours to fill the questionnaire and the researchers effectively followed-up the collection process. Since the study was conducted in an enlightened and competent environment, the respondents have a grasp and understanding of the subject matter of the research and one day was enough to fill the questionnaire. The graduate school introduced the researchers to the institutions through a letter of introduction informing the institutions that the purpose of this study was for academic awards. The letter addressed to authorities of each institution was presented to gain access. In addition, participant request form was issued by the researchers to the respondents for confidentiality and privacy purposes, and the respondents were informed that the survey is purely for the fulfilment of graduate studies and their participation is voluntary. The questionnaire consists of three sections. Section A is demographic data.

Table 2: Demographic data of the sample

\begin{tabular}{|c|c|c|c|}
\hline Variables & Employees & Freq. & Percentage \\
\hline Sex & $\begin{array}{c}\text { Male } \\
\text { Female }\end{array}$ & $\begin{array}{c}282 \\
99 \\
381\end{array}$ & $\begin{array}{c}74 \\
26 \\
100\end{array}$ \\
\hline Age & $\begin{array}{c}\text { Under } 26 \\
26-35 \\
36-45 \\
46-55 \\
56-65 \\
65 \text {-above }\end{array}$ & $\begin{array}{c}23 \\
95 \\
142 \\
105 \\
14 \\
2 \\
381 \\
\end{array}$ & $\begin{array}{c}6 \\
24.9 \\
37.2 \\
27.6 \\
3.7 \\
.5 \\
100\end{array}$ \\
\hline $\begin{array}{c}\text { Type of } \\
\text { Institution }\end{array}$ & $\begin{array}{l}\text { College of } \\
\text { education } \\
\text { Polytechnic } \\
\text { University }\end{array}$ & $\begin{array}{l}42 \\
123 \\
216 \\
381\end{array}$ & $\begin{array}{c}11 \\
32 \\
57 \\
100\end{array}$ \\
\hline $\begin{array}{l}\text { Category of } \\
\text { staff }\end{array}$ & $\begin{array}{c}\text { Academic } \\
\text { Non-academic }\end{array}$ & $\begin{array}{l}229 \\
152 \\
381 \\
\end{array}$ & $\begin{array}{c}60.1 \\
39.9 \\
100 \\
\end{array}$ \\
\hline Rank/position & $\begin{array}{l}\text { Asst. lecturer to } \\
\text { lecturer } 1 \text { and } \\
\text { equivalent } \\
\text { Senior lecturer- } \\
\text { reader } \\
\text { equivalent } \\
\text { Professor \& } \\
\text { equivalent } \\
\text { Administrative } \\
\& \text { division } \\
\text { heads }\end{array}$ & $\begin{array}{c}191 \\
38 \\
6 \\
146 \\
381\end{array}$ & $\begin{array}{c}50.2 \\
9.9 \\
1.6 \\
38.3 \\
100\end{array}$ \\
\hline $\begin{array}{c}\text { Educational } \\
\text { level }\end{array}$ & $\begin{array}{c}\text { Bachelor } \\
\text { Masters and } \\
\text { above }\end{array}$ & $\begin{array}{l}245 \\
136 \\
381\end{array}$ & $\begin{array}{l}64.3 \\
35.7 \\
100\end{array}$ \\
\hline
\end{tabular}

Section B and C are questions regarding TMP (recruitment and culture) were asked and section D: IP questions were asked; all on a Linkert scale ranging from strongly agree, agree, moderate, disagree, and strongly disagree. The scores were in the order of 1,2,3,4, and 5; and this forms the basis for measurement of variables. The scores' order was chosen based on the subject matter and the expected outcome. The researchers collected a letter of introduction from his department (Graduate School) of his institution, introducing them and purpose of research to the selected institutions. The letter addressed to authorities of each institution was presented to gain access. Additionally, requests for participation and consent letters were given to respondents for confidentiality and privacy purposes, and the respondents were informed that the survey is purely for the fulfillment of graduate studies and their participation is voluntary. Collected data were analyzed using Partial Least Square Structural Equation Modeling (Smart PLS-SEM). PLS-SEM is used to analyze composite-based path models or data. It was used because data involve more than a single-item measurement, testing of a theoretical framework from a predictive perspective that aimed at a better understanding of increasing complexity by exploring theoretical extensions, and the latent variables scores were used for follow-up analysis (Hair et al. 2017). 
The study regresses the exogenous (TRMP and TCMP) on the endogenous (EP) thus: $\mathrm{Y}=\beta_{0}+\mathrm{X}_{1}+\mathrm{X}_{2}$ (Where $\mathrm{Y}=\mathrm{EP}, \beta=$ Beta, $0=$ Constant, $\mathrm{X}_{1}=\mathrm{TRMP}, \mathrm{X}_{2}=\mathrm{TCMP}$ ).

The endogenous variable outcome is expected to have a positive and significant relationship on the exogenous variables.

\section{Population and Sample Procedure}

The conceptual and associated hypothesis is tested using the data generated through the questionnaire distributed to all randomly selected employees of IHL. The total population is 8355 employees. The respondents' sample size was determined using Taro Yamani's (1967) formula.

$$
\mathrm{n}=\frac{\mathrm{N}}{\left(1+\mathrm{N} \mathrm{e}^{2}\right)}
$$

The sample size of 382 is obtained.

\section{Data Analysis Techniques}

The selected institutions for the study include Modibbo Adama University of Technology, Yola, and American University of Nigeria, Yola, Adamawa State University, Mubi, Federal Polytechnic, Mubi; and Adamawa State Polytechnic, Yola. The study employed Composite Reliability (CR) to evaluate the model's internal consistency, the individual reliability of outer loading indicators, the average variance extracted (AVE) to evaluate convergent validity, the assessment of the discriminant validity using Heterotrait Monotrait (HTMT) and cross-loadings. They are all found in PLS-SEM. PLS-SEM was selected to enable the research to explain the relationships with the model and to examine whether the hypotheses are empirically supported (Sarstedt et al., 2013). Also, PLS-SEM is effective in explaining the interrelationship between the constructs (Sarstedt, Ringle, Henseler \& Haire, 2014)

\section{Reliability of the Item and Convergent Validity}

The outer loadings of the indicators based on reflective measurement model assessment ranged from 0.716 to 0.925 as reported in Table 1.1 below and this indicates an acceptable correlation and individual indicator's reliability because items with a loading less than 0.7 are not statistically significant (Risher, Ringle \& Sarstedt, 2019; Hair et al. 2017; Ghasemy, 2020). The researchers used PLS Algorithm to determine the Cronbach Alpha and CR of the constructs' validity. The model required Cronbach Alpha and CR of 0.7 and above to be valid and reliable. However, the researchers emphasized CR, which is a better indicator of internal consistency. $\mathrm{CR}$ has proven to be superior to Cronbach's alpha because it uses the factor loading weight scores of the model and the Average Variance Extracted (Fornell \& Locker, 1981; Risher, Ringle \& Sarstedt, 2019; Hair et al., 2017). From the results, the CR of all the reflective constructs is above 0.7 threshold value, which indicates a high level of internal consistency for all the constructs.

The convergent validity is the extent to which the construct converges to explain the variance of its items. The validity metric used to test the construct validity in this study is the average variance extracted (AVE). For AVE to be accepted, it has to have a value of 0.50 or higher, which means that the construct explains at least $50 \%$ of the variance of the items. The table below shows the result of the AVE from the survey. The result shows that the AVE of the construct based on the data analyzed is acceptable because all variables have AVE ranging from 0.576 to 0.744 , which is above 0.5 (Risher, Ringle, \& Sarstedt, 2019; Hair et al. 2017; Ghasemy, 2020). This indicates that the constructs explained above $50 \%$ of the variance of its items. 
Table 3: Measurement of Indicators, Composite Reliability, and AVE

\begin{tabular}{|c|c|c|c|c|}
\hline Construct & Factor & Loadings & $\begin{array}{c}\text { Composite } \\
\text { Reliability }\end{array}$ & AVE \\
\hline TRMP & R4 & 0.757 & 0.828 & 0.709 \\
\hline & R5 & 0.921 & & \\
\hline TCMP & C3 & 0.756 & 0.891 & 0.576 \\
\hline & C4 & 0.767 & & \\
\hline & C7 & 0.774 & & \\
\hline & C10 & 0.788 & & \\
\hline EP & C11 & 0.778 & & 0.744 \\
\hline & P5 & 0.843 & 0.921 & \\
\hline & P8 & 0.895 & & \\
\hline & P11 & 0.925 & & \\
\hline & P12 & 0.851 & & \\
\hline
\end{tabular}

Source: Field Survey Result, 2020

\section{Correlation and Discriminant Validity (AVE Diagonal)}

Correlation is the statistical tool used to determine the relationship between two or more variables or constructs. The Discriminant Validity (DV) was used to show the construct difference. The DV shows the extent to which one construct is empirically different from other constructs in the structural model. Fornel and Larcher (1981) suggested that the AVE of each construct should be compared to the square inter-construct correlation. The variance for all model's shared construct should not be higher than their Average Variance Extracted. However, this proposition has been criticized in the literature (Henseler et al. 2015). Henseler (2015) proposed that the Heterotrait Monotrait (HTMT) of correlation should be used. The HTMT is the mean value of the correlated items across constructs relative to the mean of the average correlated item measuring the same construct. DV problems occur when HTMT values are high. HTMT value above 0.9 suggests that DV is not present. However, when the constructs are conceptually distinct, a lower but conservative threshold value is recommended at 0.85 (Henseler et al. 2015). This study used the HTMT ratio to determine the constructs' correlation. The result of the HTMT shows that the data are valid and reliable for accurate prediction because the square root of the AVE of each construct is higher than the construct's highest correlation with any other construct in the reflective model, as shown in the table.

Table 4: HTMT and DV

\begin{tabular}{|l|l|l|l|}
\hline Constructs & TRMP & TCMP & EP \\
\hline TRMP & 0.841 & & \\
\hline TCMP & 0.497 & & \\
\hline EP & 0.00 & 0.056 & \\
\hline
\end{tabular}

Source: Field Survey Result, 2020

All the items have higher scores on the construct than on others; this further provides evidence of DV. This indicates that the model has discriminant and convergent validity (Anderson \& Gerbing, 1998; Henseler et al. 2015) and that the indicators were loaded satisfactorily, and measures of the construct are distinct.

The cross-factor loading shows the construct correlation results as indicated in table three below: 
Table 5: Cross- Factor Loadings

\begin{tabular}{|c|c|c|c|}
\hline FACTOR & TRMP & TCMP & EP \\
\hline R4 & 0.751 & 0.279 & 0.389 \\
\hline R5 & 0.925 & 0.326 & 0.675 \\
\hline C3 & 0.279 & 0.766 & 0.040 \\
\hline C4 & 0.299 & 0.741 & 0.046 \\
\hline C7 & 0.270 & 0.772 & 0.066 \\
\hline C10 & 0.275 & 0.800 & 0.050 \\
\hline C11 & 0.262 & 0.747 & 0.046 \\
\hline P5 & 0.554 & 0.061 & 0.855 \\
\hline P8 & 0.654 & 0.073 & 0.889 \\
\hline P11 & 0.546 & 0.078 & 0.870 \\
\hline P12 & 0.518 & 0.010 & 0.835 \\
\hline
\end{tabular}

Source: Field Survey Result, 2020

The above measure of validity and reliability shows that PLS conform to the rigidity and certainty for further extrapolation for discussion of the findings.

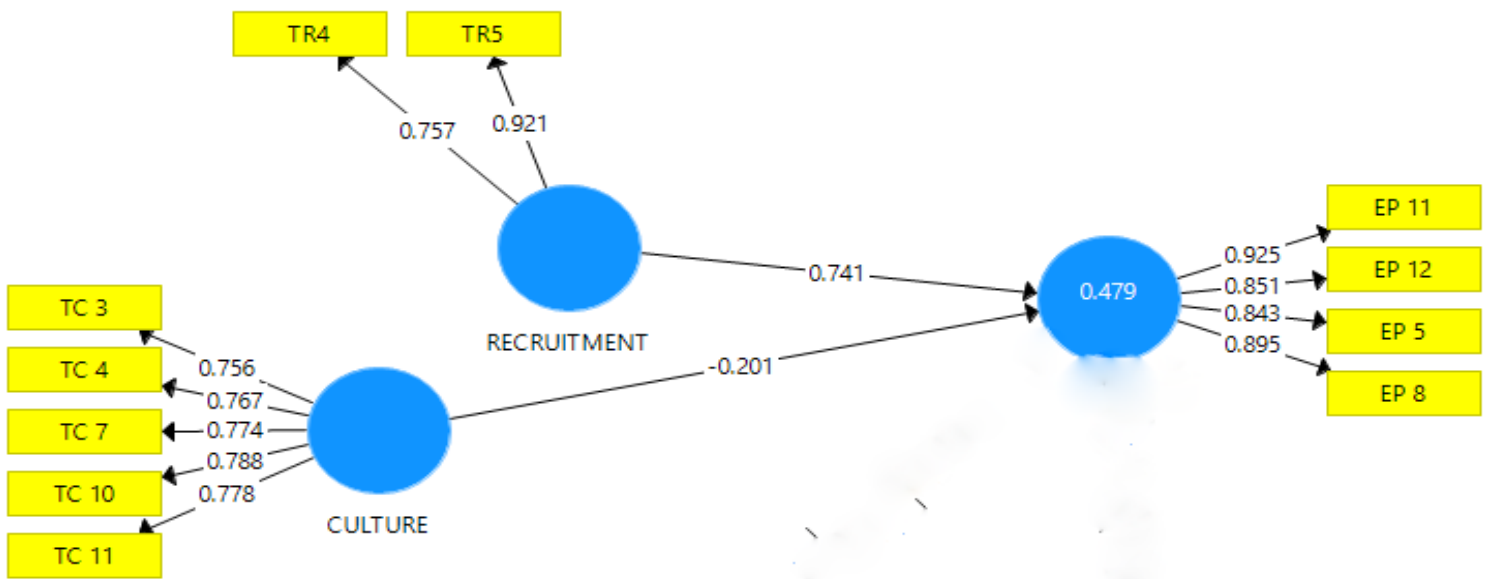

Figure 2: Model Structure

\section{Research Findings}

PLS-SEM 3.0 was used to test the model and hypotheses through a bootstrapping procedure with 1000 subsamples to examine the statistical significance of the constructs and path coefficient. The study revealed a direct positive significant relationship between TMP (TRMP) and EP at the $\beta=0.738, p=0.000$, and a direct positive significant relationship between TCMP and EP at the $\beta=0.176, p=0.001$. The direct positive significant supports and accepts hypotheses $\mathrm{H}_{1}$ and $\mathrm{H}_{2}$, respectively.

Additionally, the combined effect of TMP on EP has resulted in a significant positive $R^{2}$ (R Square) of 0.479 . The $R$-square $\left(R^{2}\right)$ is used to determine the predictive capacity of the model. The higher the R-square, the more the capacity to predict the variables and verseversa. However, $\mathrm{R}^{2}$ of $95 \%$ shows redundancy while the minimum acceptable predictive capacity is 40\% (Risher, Ringle \& Sarstedt, 2019; Hair et al. 2017).

\section{Path Coefficients of Variables}

The path coefficient is used to determine the variables' level of significance. The path coefficient of the variables shows the relationship between the exogenous (i.e., independent) and endogenous (i.e., dependent) variables in the model. The standardized indicator weight value is between -1 and +1 , 
which indicates a weak relationships and positive relationships respectively. From the table, TRMP is positively significant at $1 \%(0.01)$; talent culture practice is also significant at $1 \%(0.01)$ based on the data collected, as shown in Table 4 below.

Table 6: Path Coefficient of Variables

\begin{tabular}{|c|c|c|c|c|c|c|}
\hline \multicolumn{7}{|c|}{ Path Coefficient of Variables } \\
\hline & B & Sample Mean & SD & T-Value & P -Value & Decision \\
\hline TRMP & 0.738 & 0.734 & 0.024 & 30.678 & 0.000 & Supported \\
\hline TCMP & 0.176 & -0.146 & 0.024 & 3.349 & 0.001 & Supported \\
\hline
\end{tabular}

Source: Field Survey Result, 2020

\section{Discussion of Findings}

The research findings support the view that TMP (recruitment and culture) are positively related to EP. The findings support the view of Nafei (2016) that talent management recruitment significantly and positively influences organizational performance. Arif and Uddin (2016) agreed that flexible work schedules, excellent work climate, clear goals, career progression and preference for internal talents attract talented employees and enhance organizational performance. Mwanzi, Wamitu, and Kiama (2017) also believed that culture has a significant positive relationship with organizational performance. The findings are in collaboration with Maina (2016) and Aluko (2004), who both report that there is a strong relationship between institutional culture and employee performance and established that employees enjoyed the industrial way of life irrespective of their cultural background. This is also in line with Maina (2016), Robbins (2012), and Magee (2002), who all established that in an institution where the employees' operations are characterized by organizational culture, workers are likely to have a uniform or similar perception of the organization.

\section{Recommendations}

Based on the findings, the researchers recommend that authorities of IHL can implement and TMP programs improve employee performance through:

i. Creating an enabling environment for talent establishment and also provide talent creativity award and recognition support, meritorious recruitment based on qualification, experience, and capacity for talent survival and retention.

ii. Maintaining quality service delivery through a succession plan, consistent and fair implementation of employee's rules and policies; and allow employees participation in the decision making process.

iii. Focusing attention on exploring and developing employees through TRMP, such as organizing regular and timely induction programs for newly recruited talent, and this practice should cut across all cadres of employees within the institution.

iv. Maintaining the value and encouraging talent career growth and development as part of the operational culture by ensuring that salary increments are done meritoriously; promotional guidelines and processes are transparent, clear, and not politicized.

v. Maintaining a culture of encouraging and retaining full rank professors for a good mentorship system.

\section{Limitations and Suggestion for Future Research}

Firstly, some of the respondents, especially those at the managerial level, were generally busy and unwilling to give certain information about their institutions. However, the researchers made several efforts through visits and communication on phone calls to get adequate respondents.

Secondly, authorities of institutions were reluctant to divulge information about the performance of their students, research development as well as a student-faculty ratio. However, the researchers reassured them that the information obtained from them would be used only for the study.

Thirdly, the study was limited by the use of structured questionnaires as tools for data collection. The instruments were closed-ended and denied the respondents the chance to express their 
opinions outside the structure. Further research should focus on the impact of budgetary allocation to IHL on employee performance and the impact of talent brain drain on IHL performance.

\section{Conclusion}

The study showed that TMP (recruitment and culture) influences employee performance in IHL. The paper identified brain drain, shortage of talented employees, poor global ranking, and poor service delivery among others are the problems facing IHL in Nigeria; and TMP can be used as a strategy to address these problems. The paper, therefore, established that TMP (Recruitment and culture) have a positive significant influence on employee performance in IHL. Hence, IHL must develop and maintain effective TMP such as organizing regular and timely induction programs for newly recruited talents; salary increments and promotions should be done meritoriously; and there should be transparent, clear, and not-politicized guidelines for the promotion of talent.

\section{References}

Acar, P., \& Yener, M. I. (2016). Theoretical journey on talent management: Egalitarian and Elite approach. Press academia 2016321984

Ahlrichs, N. L (2000). Key recruitment and retention strategies for becoming an employer of choice. California: Davis-Black Publishing.

Aguinis, H. (2009). Performance Management. New Jersey, Pearson Education Limited.

Aibieye, S. \& Igiebo, H., O. (2015). Talent management and employee retention in Nigeria universities. NG-Journal of Social Development, 5(1), 23-31.

Ari, A. A., \& Uddin, M. R., (2016). Talent management and organizational performance: An empirical study in retail sector in Sylhet City, Bangladesh, Semantic scholar paper

Armstrong, M. \& Baron, A. (2004). Managing Performance: Performance Management in Action. UK: CIPD Publishing.

Asiyai, I. R. (2013). Challenges of quality in Higher Education in Nigeria in the $21^{\text {st }}$ century: Delta State University, Abraka Nigeria

Berger L. A. \& Berger D. R. (2004). The talent management handbook: creating organizational excellence by identifying, developing, and promoting your best people. New York McGrawHill.

Berger, L. A., and Berger, D. R. (2004). The Talent Management Handbook: creating a sustainable competitive advantage by selecting, and promoting the best people, $2^{\text {nd }}$ edition, New York: McGraw-Hill Companies.

Bryant, M. (2004). The portable dissertation advisor. Thousand Oaks, C.A: Corwin.

Butterfield, B. (2008). Talent management: emphasis on action. Talent management strategies for attracting and retaining the best and the brightest. CUPA-HR Journal, 59(1), 34-40.193

Collins, D. G. \& Mellahi, K., (2009). Strategic talent management: a review and research agenda. Human Resource Management Review, 19(4), 304-313

Creswell, J. W. \& Plano Clark. V. L. (2007). Designing and conducting mixed methods research. Thousand Oaks. C.A: sage

Davies, T., and Davies, R. (2010). Talent Management: a new strategy for talent management. London Gower Publishers

Gallardo-Gallardo E, dries N, Gonzalez-Cruz TF (2013). What is the meaning of talent in the world of work? Human Resource Management Review. 23(4): 290-300

Groysberg, B., and Bell, D. (2013). Talent management: Board give their companies an " $F$ ". Harvard Business Review.

Haim, H. and Abubakar, A. (2017). Strategic talent management and university performance: A theoretical perspective, European Journal of Business and Management. 9(4).

Hair, J. F., Hult, G. T. M., Ringle, C.M. and Sarstedt, M. (2017). A primer on partial least squares structural equation modeling (PLS-SEM), Sage, thousand Oaks, CA. 
Henseler, J., Ringle, C. M., \& Sarstedt, M. (2015). A new criterion for assessing discriminant validity in variance-based structural equation modeling. Journal of the academy of marketing science, 43(1), 115-135.

Hewitt A. (2012). Higher Education survey: The state of human resource effectiveness from www.aonhewitt.com.

Hosen, S., Islam, M. A., Arshad, M. M., Khan, A. M., \& Alam, M. K. (2018). Talent management: An escalating strategic focus in Bangladeshi banking industry. International Journal of Academic Research in Business and Social Sciences, 8(1), 156-166.

Islam, M. A., Jantan, A. H., Rahman, M. A., Hamid, A. B. A., Mahmud, F. B., \& Hoque, A. (2018). Talent Management for Organisational Performance Development in Bangladesh Private Industry Context. International Journal of Human Resource Studies. 8(4), 21-34

Khan, A. M., Jantan, A. H. B., Salleh, L. B. M., Dato'Mansor, Z., Islam, M. A., \& Hosen, S. (2019). The Impact of Transformational Leadership Effects on Innovative Work Behavior by the Moderating Role of Psychological Empowerment. Journal of Reviews on Global Economics, 8(1), 925-938.

Liversage H. (2015). Talent management in South Africa universities: Management and recruits' expectation and perception: North-West University, Potchefstroom Campus. http://www.insidehire.com/view/2007/11/27/lynch

Maina, J. (2016). Influence of organizational culture on performance of commercial banks in Kenya: the University of Nairobi, School of business.

Mwanzi, J., Wamitu S., Kiama M. (2017). Influence of talent management on organizational growth. IOSR Journal of Business and Management, 19(8), p 01-36.

Nafei, W. A., (2016). The impact of talent management on organizational performance: Evidence from the industrial companies in Egypt. Case Study Journal, vol. 5.

Ogbari, E., Yewande, O. A., Ogunnaike, O. O., Kehinde, O. J., (2018). Talent management as a determinant of firm performance: A conceptual approach. Covenant University, Ota, Ogun State, Nigeria.

Riccio, S., (2010). Talent management in higher education: developing emerging leaders within the administration at private colleges and universities. The University of Nebraska-Lincoln.

Ringle, C.M., Sarstedt, M., Mitchell, R. and Gudergan, S. P. (2019). Partial least squares structural equation modeling in HRM research: the International Journal of human resource management.

Salmi, J. (2009). New challenges of establishing world-class universities. World Bank publication.

Sarstedt, M., Bengart, P., Shaltoni, A. M., and Lehmann, S. (2018). the use of sampling methods in advertising research: a gap between theory and practice. International Journal of Advertising. 37(4), 650-663.

Sarstedt, M., Ringle, C. M., and Hair, J. F. (2017). Partial least squares structural equation modeling, in Homburg, C., Klarmann, M., and Vomberg, A (Eds), Handbook of market research, Springer, Heidelberg.

Tetik, S., (2016). Talent management: A review of theoretical perspective and guideline for practitioners. Faith University Turkey, Nile journal of business and economics,4(2) 40-56. 